\title{
Teaching Ethics Courses in the System of Higher Education in Russia: Problems and Prospects
}

\author{
Vladimir Tsvyk \\ Department of Ethics \\ Faculty of Humanities and Social sciences \\ Peoples ' Friendship University of Russia \\ Miklukho-Maklay str., 10/2, Moscow, Russia, 117198 \\ E-mail: tsvyk_va@pfur.ru
}

\author{
Irina Tsvyk \\ Department of Philosophy \\ Moscow Aviation Institute \\ (National Research University) \\ Miklukho-Maklay str., 10/2, Moscow, Russia, 117198 \\ E-mail: tsvykirina@mail.ru
}

\begin{abstract}
The article discusses the ethical and moral education of students in modern Russian high schools. The necessity of strengthening the educational component of the higher education system is noted. To solve the problem, we propose a more active incorporation of the ethical component into training which includes not only the interpretation of professional ethics codes of specialists in different fields of professional activity by students, but also the consideration of the problems of social and ethical issues related to the professional activity and moral assessment of future professional problems as a whole.
\end{abstract}

Keywords-ethics; ethical discipline; higher education; moral education; moral judgment; professionalism; professional ethics and moral responsibility

\section{INTRODUCTION}

Modern society has entered into a stage of development when there is a need, by using all the accumulated benefits, to reach a new qualitative state in all spheres of life, i.e. economy, social relations, culture and everyday life. Modernization's course taken by our country requires not only a huge organizational effort and scientific and technical measures of active social policy, but also to ensure the moral of this whole process. The modernization of Russian society is not possible without the ability of a person to a responsible choice of moral values and deeds, patriotism, moral high ground and safety of the individual, the humanization of its existence and communication.

The present stage of social development is characterized by a high degree of professionalization of society, by increasing complexity of its professional structure, and by rising public expectations of the representatives of various professions. The highest feature of professional development of the individual, ensuring his ability to productive and creative professional work, is professionalism as the relevant knowledge and skills, as well as the whole value system of the person to what occurs in a particular area of professional practice and specialization.

The professionalism of the individual is based on the concordance of a wide range of professional competencies (skills, abilities, knowledge, values, and ideals) of the individual with the level of public expectations of the profession [8. P. 133].

A modern professional should be able to think creatively, to solve complex problems independently, to adapt to new knowledge and technology, and to improve their skills. The most important manifestation of professionalism of the person is the ability to free creative activity which is largely due to the formation of professional culture and intellectual development of the individual as the ability to professional growth, new knowledge, and ability to solve complex professional tasks in a dynamic society [9. P. 48]. In this case, there are two factors without which creative and progressive development of any social organism is just inconceivable, and civilization in general is, firstly, professional excellence of the individual based on the achievements of modern science, education and social practices, and, secondly, moral and spiritual elevation of man, his moral and ethical values.

\section{MORAL EDUCATION POTENTIAL}

In today's modernizing Russian society, the system of higher education has radically changed the priorities of social and personal choice. Education today is increasingly seen not only as a process of acquiring systematized knowledge but as the preparation and inclusion of the individual into various spheres of society. In this context, it is very important to define meaningful boundaries of the concept "education» ethical aspects of which are to be determined in each case because of its ambiguity. Education is:

- a social institution whose main function is to prepare the individual and the inclusion in different spheres of society;

- the combination of systematized knowledge, skills (especially professional) acquired by the individual (alone or in the course of training in special education);

- the process of assimilation of knowledge, i.e., training, education;

- individual educational level of comprehensive knowledge and of a high degree of culture; 
- education of a society or the people as the level of civilization of the country. For ethics, in all these cases, the determining factor is the consideration of education not only in terms of its enlightenment but mainly as "education" and "creation" of the individual.

Moral education is determined by its status of a social and political institution of the state. It is a universal and moral way of life of the people which serves the strengthening of its statehood, the development of history and culture, the formation of spiritual and moral values, and civic consciousness, always provided that national identity is not limited to the knowledge of only their ethnicity. It reflects the ethnic installation and value orientation as well as the tolerant attitude to the culture of all peoples living side by side. This forms the man-citizen, a person who is integrated in the multinational culture and the society through education, particular ethics which creates itself basing on adequate forms of educational and social activities.

Creating an integrated system of education and educating professionals in higher education that combines training and humanistic orientation can be realized only by relying on the triad:

- provide a new generation for fundamental knowledge at the latest science level;

- formation of skills and willingness to work with competence in the chosen field of activity;

- training highly educated, intelligent, spiritually rich and highly moral experts corresponding to the new social needs.

\section{ETHICAL DiSCIPLINES IN THE S YSTEM OF SOCIAL AND HUMANITARIAN EDUCATION}

The main purpose of training in higher education is to acquire specific knowledge and skills necessary for the successful implementation of a particular type of professional activity. In addition, professional interest not weighed down by universal moral values can cause professional narrowness; therefore a significant component of vocational training should be a moral education [4. P.137].

Introduction of an ethical component in working curricula of universities is currently one of the most urgent tasks facing the Russian higher education system. Relevancy of this issue is defined as by the transition to European educational standards as well as by amplifying the gap between the specialized knowledge and skills obtained in the course of vocational training and social and humanitarian knowledge, contributing to the formation of moral and social position of the individual, his professional and moral education.

The importance and necessity of moral education in high school is recognized today in full. The process of training new values, complicated by fundamental nature of their status, is recognized as one of the main goals of high school. [5] It is also a growing understanding that this goal can be realized only with the harmonious combination of natural, technical, economic, and human sciences in vocational training, regardless of the particular specialization training. The need to strengthen the educational component of the higher education system determines the growth of interest and attention to ethics as to the study of morality, as to a practical philosophy capable today to equip the human ability to properly assess its acts harmonize the activities and interests of each person to the activities and interests of a particular collective and society in general.

Ethics as an essential part of human knowledge, occupies a special place in modern culture. This is due, on one hand, to the increased requirements of the person as a subject of technotronic "civilization of knowledge", and, on the other hand, to the anthropological crisis which is expressed in the physical and spiritual human degradation and identity crisis. In addition, the rising complexity of social change requires an increase in the degree of responsibility and professionalism; a high level of technological progress creates an unprecedented situation where the moral choice of one person may influence the fate of many.

Specificity of ethics consists in the fact that it is important and necessary in the education system, aimed not only at training and expansion of mental horizons but also at education, improvement and spiritual growth of the individual. In modern conditions, the whole institution of culture, science, and education must be permeated by the ethical will without which it cannot perform its main task, i.e. to raise a mature and moral person, a high-level professional.

The processes of globalization in the world lead to the internationalization of higher education in Russia. A prerequisite of this is the creation of the university international humanitarian environment based on the principles of democracy, tolerance and respect for other cultures. An important part of modern higher education is also the understanding of the processes occurring in the world, the ability to analyze and moral evaluation [6. P. 176]. The scale of modern values of the individual should be designed taking into account the humanitarian vector which direction is fully reflected in a variety of ethical disciplines.

The interest in ethics is growing worldwide. Ethics lectures are successfully delivered to students, graduate students, and students of Advanced Training from various universities and research centers in our country and abroad. But with evident ethical perspective, the importance of the state of ethics courses in the system of modern Russian education remains problematic. At the same time, the system of European education, an integral part of which Russian education in the framework of the Bologna process is intended to become, widespread variety of ethical discipline, especially courses of applied ethics, in particular the medical, biological, environmental, technical ethics. We, unfortunately, have few analogues despite their obvious relevance and urgency.

It should be noted that, recently in our country, not only research but scientific and pedagogical work in the field of ethics problems has been enhanced due to the obvious pragmatic reasons, i.e. obvious shortage of specialists in the field of ethics for teaching a wide range of ethical disciplines so demanded today in the system of higher and secondary 
special school. The Department of ethics at Moscow State University after Lomonosov, St. Petersburg State University, and other specialized departments of Russian universities conduct active training ethics specialists capable of teaching ethical courses in higher education. New departments and research centers on the study of ethical problems and teacher training are being created. In particular, the Department of Ethics in 2010 opened at the Faculty of Humanities and Social Sciences at Russian Peoples' Friendship University (PFUR).

Today, the leading Russian universities of social and humanitarian profile deliver a wide range of ethical disciplines. For example, at the Faculty of Humanities and Social Sciences of Russian Peoples' Friendship University, students can take a course in ethics, history of ethics, the history of ethical teachings, modern Western ethics, the ethics of science, problems of modern humanities, contemporary issues of ethics, the general theory of morality, "Big Ethics" by Aristotle, the problem of good and evil in the Russian philosophy, ethics of world religions, moral problems of intercultural communication, current moral problems of the modern world, the ethical aspects of the art world, the spiritual and moral foundations of Russian art, spiritual and moral heritage of the Russian Diaspora, professional ethics such as foundations of the general theory and others. [7. P. 8]. Most of these courses are within the specialization of philosophy.

At the same time, ethical discipline takes into account the specialization of the students and covers other specialties of the Faculty of Humanities and Social Sciences. In Arts and Humanities courses, ethical aspects of art, postmodern ethics, culture and religions of the world is delivered. In Sociology courses it is "professiology"; "professional ethics of sociologist" is studied. In Political science courses, there are political ethics and professional ethics. In International Relations, we deliver professional ethics and contemporary problems of the humanities. In State and municipal management courses, administrative ethics, the ethics of state and municipal services, etc. are studied. The terms of ethical disciplines are periodically expanded with due regard to curriculum opportunities of various specialties. This successful experience, from our point of view, can be claimed by other Russian universities.

In our deep conviction, the most important direction of educational work in the field of ethics in Russian universities is teaching professional ethics courses in the system of higher education, especially in socio-humanitarian orientation. Professional ethics as a fully fledged part of the ethical theory has always stood out in the system of ethical knowledge by its applicative, practical nature. One of its most important tasks is to specify general ethical regulators of economic or other practical activity of a man in relation to a particular profession. Professional ethics requirements are applied to everybody without exception in certain professional areas, and their awareness and implementation is a prerequisite for the success and effectiveness of their joint activities. Therefore, in recent years, the importance of professional ethics in the various fields of human activity has immeasurably increased.
For good reason, the professional ethics courses are widespread in the European education system. An answer to a demand of the time, as well as the realization of tasks put by PFUR Rector Academician V.M. Filippov to humanitarian education of students of all fields and specialties, is the course delivered by lecturers of the department in various areas of the Faculty of Humanities and Social Sciences and other faculties of the People's Friendship University called the course of "Professional Ethics", taking into account the specialization of students, i.e. "Professional ethics of journalists", "Professional legal ethics", etc. Topical issues of medical, environmental, computer ethics, professional ethics of lawyers and journalists are developed. I would like to mention that those ethics courses in the curriculum are available for selection and, as a rule, are popular with students.

\section{Specifics In TeACHING Ethics IN TECHNICAL COLLEGES}

All of the abovementioned is relevant today for technical colleges. The contradictory nature of modern scientific and technological progress has special, higher social, moral and ethical requirements for engineering and technical staff. The degree of responsibility in modern society is high. Therefore, professional engineering today is defined not only by his professional knowledge and skills, but also by the civil maturity of personality, his psychological stability, a sense of patriotism, moral reliability [3. P. 96].

The inclusion in the curricula of training engineers of humanitarian subjects in which, as a rule, issues of ethics are raised primarily due to the currently prevailing humanistic principles in higher education worldwide. Courses in ethical issues of engineering activity are read at the Massachusetts Institute of Technology, Stanford University, California Institute of Technology and other leading universities in the USA and Europe [1. P. 86].

The introduction of the ethical component in the working training program of technical colleges is currently one of the most urgent tasks facing the Russian higher school.

Relevancy of this issue is defined as by the transition to European educational standards as well as by amplifying the gap between the specialized knowledge and skills obtained in the course of vocational training and social and humanitarian knowledge, contributing to the formation of moral and social position of the individual, his professional and moral education.

Regarding the Russian educational system in the teaching of the humanities, there is still a strong differentiation but with no serious attempts at constructive synthesis. In the preparation of technicians and engineers in technical colleges due attention to the study of the humanities as well as consideration of the problems of social and ethical issues related to engineering work, moral evaluation of art in general are not always given.

The cornerstone in a panel discussion on this topic by experts was the question of whether to create a specialized course on ethical issues and social implications in the 
development and application of technical devices, or to distribute the ethical issues at different courses throughout the curriculum. The problem of the lack of students' time for the fundamental training in natural sciences and mathematics in the Russian technical universities brings to the fact that in most cases the second approach prevails. However, with this approach the most important for teachers is not to "except ethics for minor problems and thoroughly integrate the ethical content of the technical training courses context" [2].

There are a number of problems of such address in the issue of ethics education in technical colleges. Firstly, there is a danger that when the ethical component in the curriculum of special disciplines is included, the course can be overloaded, which will eventually lead to a denial or reduction of attention to the necessary basic technical issues and poor training. Secondly, in technical colleges there can be felt the shortage of teachers with experience in teaching ethical disciplines. It is necessary to take into account the specific nature of ethics as of a philosophical discipline which is fundamentally different from that of which most teachers of technical courses are familiar with. In the absence of teachers' professional ethical disciplines philosophical basis for the teaching of these subjects, ethics can be purely formal addition to the course, and the issues that it addresses will be considered last, if at all, they will be given attention. In such a situation, carrying out this task on their own, teachers "can fall into the trap of preaching their own moral code, instead of asking questions, developing possible responses, as well as the studying grounds" instead of supplying students with the necessary amount of knowledge and methodological tools for active and intelligent solutions of ethical problems.

Finally, the existing academic standards with their limited number of training hours will not allow including ethical issues in technical education programs so that they are fully explored and made out. In such circumstances, any ethics training may be too simplistic or even misleading.

The issue of ethics education and training students of technical colleges seems to us as needed to be introduced into the curricula of various technical specialties of separate ethics courses such as, for example, "Professional Engineer Ethics", "Computer Ethics", "Engineering Ethics", "Ethics of business communication" "Ethics of science", "Ethical Principles of scientific research", etc. [10. P. 134].

Professional ethics is designed to hold a special place in the ethical education of an engineer. It is in a technical college when the foundation of professional culture of the engineer is laid. It is an integral part of the personal professional responsibility and commitment to professional ethics in engineering [11. P. 94-95]. Today, however, not all educational standards in technical fields and professions clearly define requirements for the results of development by students of professional ethics, despite the fact that the requirements for the formation of competence in the field of professional ethics as an important component of preparedness of the expert to conduct an independent engineering activities are contained in the criteria for Engineering Association Education of Russia (RAEE) for professional public accreditation of educational programs in accordance with standards of the International engineering alliance (IEA) [12]. This gap needs to be filled because, in today's society regarding the process of training the formation of a sustainable moral outlook, active living position rife with capacity for moral will and adequate moral evaluation of their professional activities and engineering solutions becomes very important for the future engineer. All this a specialist graduate of a technical college can and should receive in the course of vocational training in high school in the framework of ethical discipline courses which can include both the ethics of science, engineering ethics, computer ethics, business ethics, research ethics, ethics and psychology teamwork.

\section{CONCLUSION}

In summary, it should be noted that the introduction of ethical education in modern higher education seems relevant, timely and necessary in the context of humanization of higher education in Russia.

Philosophical character of Ethics enables it to annex moral values to different social phenomena and processes, primarily for labor and professional activities. One of the most important criteria for the moral evaluation of the quality of professional work and the individual worker becomes the professionalism implying not only a set of specific professional knowledge and skills, but also the moral character of a specialist, the implementation of his professional ethics requirements, and the ability to guide his own professional activity as a universal and professional moral norms.

The value of ethics courses in modern universities is huge because, in the absence of carefully developed didactic on ethical disciplines included in a learning process, moral education of the people becomes more difficult. Moral education is based, inter alia, on ethical knowledge and the ability to analyze human behavior from the perspective of moral and ethical standards of the society.

Today, among other ethical disciplines in modern Russian high schools, professional ethics acquires particular importance. By studying the specific conditions of implementation of the general moral requirements in the light of the social role of the representative of a particular profession, professional ethics finds in practice such kinds of behavior which enhance the effect of general moral requirements, and fixing them as normal, helps in the course of their professional activity future specialists-professionals fit into the general moral system.

\section{REFERENCES}

[1] Gasheva Y.V. Engineering ethics: the problem of the formation and evaluation of competence // Higher education in Russia. -2014. -№ 6. -P. 85-92.

[2] Malyuk A.A., Polyanskaya O.Y., Alekseeva I.Y. Ethics in the field of information technology. - M., 2011. $-346 \mathrm{p}$. 
[3] Moiseenko M.V. On the formation of patriotism and spirituality in modern Russian youth // Bulletin of Peoples' Friendship University of Russia. Series: Philosophy. -013. -№3. P. 96-103.

[4] Muhametzhanova V.S. The moral and ethical aspect of professionalism // Bulletin of Peoples' Friendship University of Russia. Series: Philosophy. -2013. -№3. -135-142.

[5] Savvina O.V. - University Mission // Modern Education. -2012. -№2. P. 155-179.

[6] Tsvyk A.V. The moral foundations of international relations // Bulletin of Peoples' Friendship University of Russia. Series: Philosophy. - 2014. - №2. - P. 176-183.

[7] Tsvyk V.A. Chair of Ethics at the Peoples' Friendship University of Russia // Bulletin of Peoples' Friendship University of Russia. Series: Philosophy. -2013. - №3. - P. 7-9.

[8] Tsvyk V.A. Professional ethics: foundations of the general theory. 3rd ed. - M.: Publishing the Peoples' Friendship University, 2014. -288 p.

[9] Tsvyk V.A. Socio-professional status of the individual and the prestige of the profession // Bulletin of Tyumen State University. Socio-economic and legal research. -2009. -№ 4. P. 44-52.

[10] Tsvyk I.V. Computer ethics and intellectual safety problems // Bulletin of Peoples' Friendship University of Russia. Series: Philosophy. -2013. -№3. P. 125-135.

[11] Tsvyk I.V. - Professional Engineer Ethics // Professional ethics in modern society. -M., 2011, P. 88-101.

[12] International Engineering Alliance. Graduate Attributes and Professional http://www.washingtonaccord.org/IEA\%Grad\%Attr\%Prof\% Competencies.pdf. 